\title{
PENGARUH TEMPERATUR PELEBURAN PADA PENGECORORAN LOGAM PADUAN AL-Si TERHADAP KEKERASAN DAN STRUKTUR MIKRO
}

\author{
Sulis Dri Handono \\ Jurusan Teknik Mesin Universitas Muhammadiyah Metro \\ Jl.Ki Hajar Dewantara No.166 Kota Metro Lampung 34111, Indonesia \\ esdehaa@gmail.com
}

\begin{abstract}
Abstrak
Penelitian ini bertujuan untuk mempelajari pengaruh temperatur peleburan terhadap struktur mikro dan kekerasan. Paduan yang digunakan adalah Al-Si 7,79\%. Paduan aluminium - silikon memiliki sifat mekanis yaitu mampu cor,mampu las dan ketahanan korosi yang baik. Pengamatan yang dilakukan terhadap struktur mikro memperlihatkan bahwa paduan Al-Si 7,79\% menunjukkan beberapa pola yang sama yaitu kecenderungan fasa silikon akan berubah menjadi serpihan tebal dan primary silikon cenderung berubah semakin besar. Kondisi ini disebabkan terjadinya peningkatan waktu pembekuan seiring dengan peningkatan temperatur peleburan dan cetakan. Penelitan ini menggunakan tiga variasi temperatur peleburan yaitu $700^{\circ} \mathrm{C}, 750^{\circ} \mathrm{C}$, dan $800^{\circ} \mathrm{C}$. Kekerasan secara umum akan meningkat seiring dengan peningkatan temperatur peleburan. Kekerasan tertinggi didapatkan pada temperatur peleburan $750^{\circ} \mathrm{C}$ yaitu $79,94 \mathrm{BHN}$.
\end{abstract}

Kata kunci : Temperatur peleburan,paduan Al-Si,struktur mikro,kekerasan

\section{PENDAHULUAN}

\section{Pengecoran}

Usaha pengecoran logam mempunyai peranan strategis dalam perekonomian nasional terutama dalam industri otomotif. Proses Pengecoran (CASTING) adalah salah satu teknik pembuatan produk dimana logam dicairkan dalam tungku peleburan kemudian di peleburankan kedalam rongga cetakan yang serupa dengan bentuk asli dari produk cor yang akan dibuat. Pemilihan jenis bahan yang akan digunakan dalam pengecoran mempunyai fungsi penting dalam melaksanakan proses pengecoran. Tiap-tiap bahan yang akan dipergunakan mempunyai sifat dan karakter yang berbeda-beda, masing-masing mempunyai keunggulan dan kelemahan tersendiri.[1]

Aluminium tidak hanya dimanfaatkan untuk peralatan rumah tangga, tetapi juga digunakan pada berbagai bidang dan jenis industri, antara lain untuk material pesawat terbang, pembungkus produk di industri makanan, komponen mesin, elektronik, dan sebagainya. Contoh paduan yang sering dipergunakan untuk bagian-bagian mesin adalah Al-Si, Al-Cu-Si dan Al-Si-Mg. Sedangkan untuk bagian mesin yang tahan panas adalah Al-Cu-Ni-Mg, Al-Si-Cu-Ni-Mg, dan untuk bagian yang tahan korosi adalah AlMg.
Alumunium
Aluminium ditemukan ditemukan oleh sir Humprey Davy pada tahun 1809 sebagai suatu unsur, dan pertama kali direduksi sebagai logam oleh H.C. Oesterd tahun 1825. Secara industri tahun 1886, Paul Heroult di Perancis dan C.M. Hall di Amerika secara terpisah telah memperoleh logam.
Aluminium merupakan logam ringan mempunyai ketahanan korosi yang baik dan hantaran listrik yang baik dan sifat-sifat yang baik lainnya sebagai sifat logam. Aluninium didapat dari alumina dengan cara elektrolisa dari garamnya yang terdifusi. Aluminium didapat dalam keadaan cair dengan elektrolisa umumnya mencapai kemurnian 99,85\% berat. 
Dengan mengelektrolisa kembali dapat dicapai kemurnian 99,99\%.[2]

Tabel 1. Sifat-sifat fisik aluminium

\begin{tabular}{|l|l|l|}
\hline \multirow{2}{*}{\multicolumn{1}{|c|}{ Sifat-sifat }} & \multicolumn{2}{c|}{ Kemurnian $\mathrm{Al}(\%)$} \\
\cline { 2 - 3 } & \multicolumn{1}{|c|}{99,996} & \multicolumn{1}{c|}{$>99,0$} \\
\hline Massa jenis $\left(\mathrm{kg} / \mathrm{m}^{3}\right)$ & 2,6989 & 2,71 \\
Titik cair $\left({ }^{\circ} \mathrm{C}\right)$ & 660,2 & $653-657$ \\
Panas Jenis $\left(\mathrm{cal} / \mathrm{g} .{ }^{\circ} \mathrm{C}\right)\left(100^{\circ} \mathrm{C}\right)$ & 0,2226 & 0,2297 \\
Hantaran listrik $(\%)$ & 64,94 & $59($ dianil $)$ \\
Tahanan listrik koefisien & & \\
temperatur $\left(/ /^{\circ} \mathrm{C}\right)$ & 0,00429 & 0,0115 \\
Koefisien pemuaian $\left(/{ }^{\circ} \mathrm{C}\right)$ & $23,86 \times 10^{-6}$ & $23,5 \times 10^{-6}$ \\
Jenis Kristal, konstanta kisi & $f c c, \mathrm{a}=4,013$ & $f c c$, \\
& $\mathrm{kX}$ & $\mathrm{a}=4,04 \mathrm{kX}$ \\
\hline
\end{tabular}

Tabel 2. Sifat mekanik aluminium

\begin{tabular}{|c|c|c|c|c|}
\hline \multirow{3}{*}{ Sifat-sifat } & \multicolumn{3}{|c|}{ Kemurnian Al (\%) } & \\
\hline & \multicolumn{2}{|c|}{99,996} & \multirow{2}{*}{$\frac{>99,0}{\text { Dianil }}$} & \multirow[b]{2}{*}{$\mathrm{H} 18$} \\
\hline & Dianil & $\begin{array}{l}75 \% \text { dirol } \\
\text { dingin }\end{array}$ & & \\
\hline $\begin{array}{l}\text { Kekuatan tarik } \\
\left(\mathrm{kg} / \mathrm{mm}^{2}\right)\end{array}$ & 4,9 & 11,6 & 9,3 & 16,9 \\
\hline Kekuatan mulur & & & & \\
\hline$(0,2 \%)\left(\mathrm{kg} / \mathrm{mm}^{2}\right)$ & 1,3 & 11,0 & 3,5 & 14,8 \\
\hline Perpanjangan (\%) & 48,8 & 5,5 & 35 & 5 \\
\hline Kekerasan Brinell & 17 & 27 & 23 & 44 \\
\hline
\end{tabular}

\section{TINJAUAN PUSTAKA}

\section{Pengujian Sifat Fisis dan Mekanis}

Sifat-sifat khas bahan industri perlu dikenal secara baik, karena bahan tersebut digunakan untuk berbagai keperluan dalam berbagai keadaan. Sifat-sifat bahan yang diinginkan sangat banyak, termasuk sifat-sifat mekanik (kekuatan, kekerasan, kekakuan, keliatan, keuletan, kepekaan takikan), sifatsifat hantaran listrik, sifat magnet, sifat termal (panas jenis, pemuaian, konduktivitas), sifatsifat fisik (ukuran massa jenis struktur), sifatsifat teknologi (mampu mesin, mampu keras) dan masih banyak lagi.Pengujian yang dilakukan pada bahan coran ini adalah pengujian sifat fisik dan mekanik bahan coran meliputi pengujian komposisi kimia dan pengujian struktur mikro.[3]

\section{Pengujian Struktur Mikro}

Pengujian ini untuk mempelajari karakteristik struktur dari logam, baik logam murni atau logam paduan. Pengujian ini merupakan salah satu pengujian fisis yang bertujuan untuk mengamati besarnya butiran dan kristal yang ada, serta mengamati bentuk, ukuran dan distribusi dari fase lain.[4]
Tabel 3. Larutan bahan etsa (Samsudin, Pengujian Bahan Logam).

\begin{tabular}{|l|l|l|}
\hline \multicolumn{1}{|c|}{ Material uji etsa } & \multicolumn{1}{c|}{ Bahan etsa } & \multicolumn{1}{c|}{ Komposisi } \\
\hline Baja & $\mathrm{H} \mathrm{NO}_{3}$ & $1-5 \mathrm{Cc}$ \\
& Alkohol & $100 \mathrm{Cc}$ \\
\hline $\mathrm{Cu}$ & $\mathrm{Cr} \mathrm{O}(15 \%)$ & $50 \mathrm{Cc}$ \\
& $\mathrm{H} \mathrm{Cl}$ & 2 tetes \\
\hline $\mathrm{Al}$ & $\mathrm{HF}$ & $10 \mathrm{Cc}$ \\
& $\mathrm{H} \mathrm{Cl}$ & $15 \mathrm{Cc}$ \\
& Air & $90 \mathrm{Cc}$ \\
\hline
\end{tabular}

Pengujian Kekerasan

Kekerasan didefinisikan sebagai ketahanan sebuah benda terhadap penetrasi atau daya tembus dari bahan Menurut Van Vliet (1983) kekerasan adalah sifat ketahanan bahan terhadap desakan ke dalam yang tetap, disebabkan oleh sebuah alat pendesak dengan bentuk tertentu di bawah pengaruh gaya tertentu. Ada tiga macam pembebanan untuk pengujian kekerasan yaitu :

1. Goresan,

2. Menjatuhkan bola, dan

3. Penekanan.[5]

\section{Pengujian Kekerasan Brinell}

Pengukuran kekerasan

Brinell menggunakan penumbuk (penetrator) yang terbuat dari bola baja. Metode ini dilakukan dengan mengindentasi dengan indentor pada permukaan benda uji dengan beban tertentu kemudian bekas indentor diukur. Bekas indentasi pada kekerasan Brinell memberi keuntungan pada material tidak homogen sehingga beban yang diterima lebih merata misalnya pada paduan Alumunium. Selain itu, kekerasan Brinell juga tidak begitu dipengaruhi oleh goresan dan kekerasan permukaan dibanding dengan uji kekerasan lainnya. Angka kekerasan Brinell dapat ditentukan dengan persamaan berikut:

$$
B H N=\frac{P}{\frac{\pi}{2} D\left(D-\sqrt{D^{2}-d^{2}}\right)}
$$

Dengan :

$$
\begin{aligned}
& \text { BHN = angka kekerasan Brinell }\left(\mathrm{Kg} / \mathrm{mm}^{2}\right) \\
& \mathrm{P}=\text { pembebanan }(\mathrm{Kg}) \\
& \mathrm{D}=\text { diameter indentor }(\mathrm{mm}) \\
& \mathrm{d}=\text { diameter bekas injakan }(\mathrm{mm})
\end{aligned}
$$

Untuk lebih jelasnya tentang mekanisme pengujian kekerasan Brinell dapat dilihat pada skema pengujian pada gambar 1 


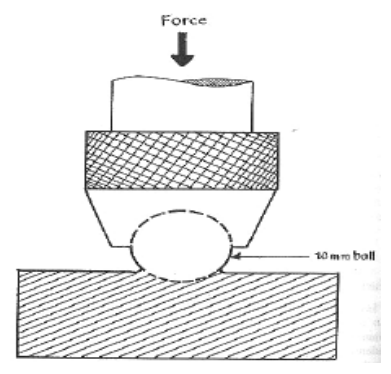

Gambar 1. Skema Pengujian Kekerasan Brinell

\section{METODE PENELITIAN}

\section{Peralatan yang digunakan}

Penelitian ini dilakukan dengan tahap persiapan material yaitu Al-Si 7,79\%. Selanjutnya setelah mempersiapkan peralatan yang diperlukan yaitu proses peleburan pada tungku menggunakan bahan bakar gas. Temperatur peleburan dijaga sesuai dengan tiga variasi penelitian yaitu 7,750 dan $800^{\circ} \mathrm{C}$.

\section{HASIL DAN PEMBAHASAN}

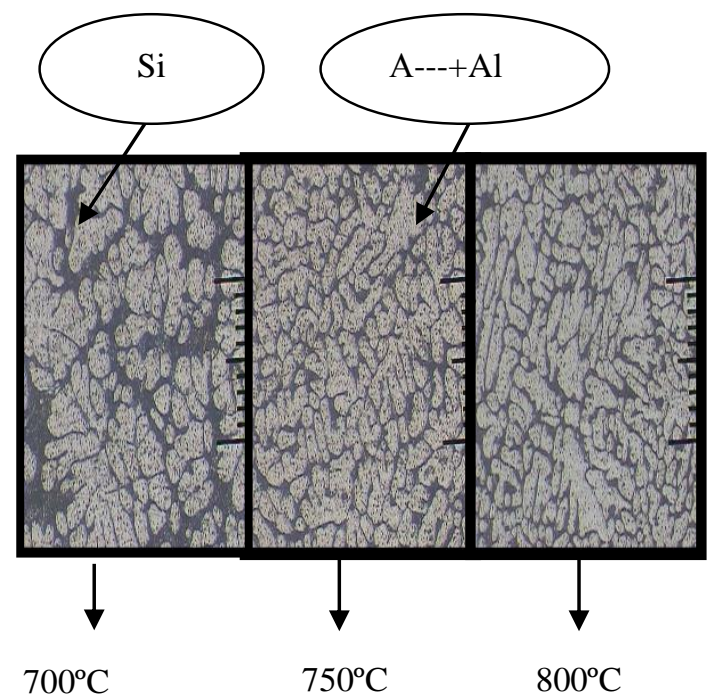

Gambar 2. Struktur Mikro Paduan Al Si 7,79

$\%$ Dengan Temperatur Peleburan $700^{\circ} \mathrm{C}$, $750^{\circ} \mathrm{C}, 800^{\circ} \mathrm{C}$

Pengaruh Temperatur Peleburan terhadap Struktur Mikro dan Kekerasan

Kekerasan bahan $\mathrm{Al}$ Si 7,79 \% akan berkurang dengan meningkatnya temperatur peleburan. Hal ini menyebabkan bertambahnya waktu pembekuan dan daerah tumbuh fasa silikon sehingga pemisahan terjada secara sempurna fasa silikon berubah dari serpihan menjadi globular dan silicon primar kecil menjadi silicon primar besar. Perubahan ini dapat dilihat pada gambar diatas jika dibandingkan dengan silicon globular, struktur silikon primar memiliki karakteristik mekanis yang lebih rendah. Temperatur peleburan mempengaruhi pembentukan struktur mikro yang berpengaruh terhadap nilai kekerasan, peningkatan temperatur peleburan akan mengurangi nilai kekerasan dengan terbentuknya silikon primer.

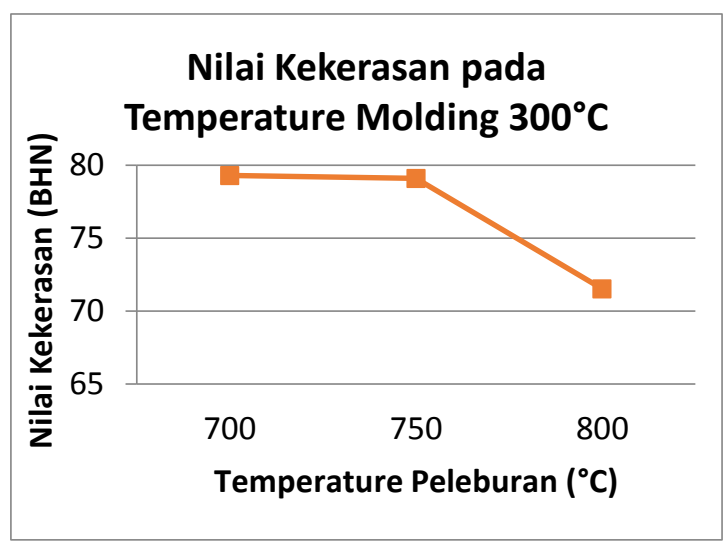

Gambar 3. Grafik Pengaruh Temperatur Peleburan Temperatur Molding Terhadap Nilai Kekerasan

Hasil pengujian kekerasan yang terlihat dalam grafik. Kekerasan bahan Al Si 7,79\% akan berkurang dengan meningkatnya temperatur peleburan. Saat temperatur peleburan mengalami kenaikan akan menyebabkan bertambahnya waktu pembekuan dan daerah tumbuh fasa silikon.Fasa silikon berubah dari serpihan menjadi globular dan silicon primar kecil menjadi silicon primar besar. Perubahan ini dapat dilihat pada gambar diatas jika dibandingkan dengan silicon globular, struktur silikon primar memiliki karakteristik mekanis yang lebih rendah. Temperatur peleburan mempengaruhi pembentukan struktur mikro yang berpengaruh terhadap nilai kekerasan, peningkatan temperatur peleburan akan mengurangi nilai kekerasan dengan terbentuknya silikon primer.

\section{Kesimpulan}

Kesimpulan dari penelitian ini adalah : 
1. Kekerasan tertinggi didapatkan pada temperatur peleburan $750^{\circ} \mathrm{C}$ dengan yaitu 79,94 BHN

2. Struktur mikro mempunyai hubungan terhadap nilai kekerasan yaitu fase aeutektik silicon yang terbentuk akan semakin merapat dan mengecil jika nilai kekerasannya tinggi.

\section{DAFTAR PUSTAKA}

[1] Bilfaqih, Y. (2015). Esensi Penyusunan Materi Pembelajaran Daring. Yogyakarta: Deepublish.

[2] T, D. (2015). TOKSIKOLOGI LINGKUNGAN. Yogyakarta: Penerbit Andi.

[3] Rahayu, I. (2007). Praktis Belajar Kimia. Bandung: PT Grafindo Media Pratama.

[4] Teknologi, I. B. (2009). Menuju abad 21: Iptek pemacu pembangunan bangsa. Jakarta: BPP Teknologi.

[5] Smallman. (1999). Met. Fsk Modern \& Rkys Material. Jakarta: Erlangga. 